\title{
Clinical Manifestation of Gastroesophageal Reflux among Children with Chronic Constipation
}

\author{
Seyed Mohsen Dehghani ${ }^{1}$, Reza Poorghaiomi ${ }^{2}$, Hazhir Javaherizadeh ${ }^{3, *}$
}

1. Gastroenterohepatology Research Center, Shiraz University of Medical Sciences, Shiraz, Iran

2. Department of Pediatrics, Nemazee Teaching Hospital, Shiraz University of Medical Sciences, Shiraz, Iran

3. Alimentary Tract Research Center, Ahvaz Jundishapur University of Medical Sciences, Ahvaz, Iran

\section{* Corresponding Author:}

Hazhir Javaherizadeh, MD Associate Professor of Pediatric Gastroenterology, Alimentary Tract Research Center, Ahvaz Jundishapur University of Medical Sciences, Ahvaz, Iran

Telefax: +986134443051

Email: Hazhirja@yahoo.com

Received: 28 Dec. 2019

Accepted: 28 May. 2020

\section{ABSTRACT}

\section{BACKGROUND}

Functional gastrointestinal system diseases (FGIDs) are a group of childhood disorders, our knowledge of which is relatively limited. More importantly, the different subgroups among such a disease group are closely interrelated, and their natural courses and interrelations have yet to be fully clarified. Functional constipation and gastroesophageal reflux disease (GERD) are most frequently seen among this group. However, evidence as to whether any relationship exists between them is limited. In this study, we tried to examine the existence or absence of this relationship.

\section{METHODS}

First, patients with functional constipation were identified based on ROME III criteria, which included 205 patients. All patients were classified into two groups of 185 and 20 patients based on their ability to respond to the questions. Then age, sex, duration of constipation, treatment, and symptoms associated with reflux were examined based on the GERD questionnaire (in case group 185 ) and I-GERD (in case group 20). Score $>11$ in the GERD questionnaire and score $>15$ in the I-GERD questionnaire were considered as reflux disease. The variables that were evaluated using Chi-square and Fisher exact tests using SPSS software version 19 included age, sex, the onset of constipation, constipation duration, duration of treatment of constipation, ROME III criteria, and symptoms associated with reflux.

\section{RESULTS}

In the current study 205 subjects were included ( girls $=49.8 \%$, boys $=50.2 \%$ ). The mean age of the children was $5.51 \pm 3.15$ years. Among the Rome III criteria, the most frequent were retentive posturing, painful defecation, history of large stool defecation, defecation less than 2 times per week, stool accumulation in the rectum, and fecal incontinency more than once a week, respectively. The lowest symptom among people with chronic constipation was fecal incontinency. Also, $46.8 \%$ of all patients in the study had a positive familial history. In general, there were 29 patients (14.1\%) with reflux out of the 205 patients with functional constipation. In the present study, no significant relationship was found between Rome III criteria and reflux.

\section{CONCLUSION}

The frequency of GERD among cases with constipation was $14.1 \%$. There was no significant relationship between Rome III criteria and reflux.

\section{KEYWORDS:}

Reflux, Constipation, Children

Please cite this paper as:

Dehghani SM, Poorghaiomi R, Javaherizadeh H. Clinical Manifestation of Gastroesophageal Reflux among Children with Chronic Constipation. Middle East J Dig Dis 2020;12:178181. doi: $10.34172 /$ mejdd.2020.180.

\section{INTRODUCTION}

Functional constipation is one of the most frequent causes of children visits to pediatric gastroenterology clinics. Gastroesophageal reflux disease (GERD) is one of the most common esophageal problems in children. Both problems 


\begin{tabular}{|c|c|c|}
\hline \multirow{2}{*}{ Defecations $=<2 /$ week } & Yes & $119(58 \%)$ \\
\hline & No & $86(42 \%)$ \\
\hline \multirow{2}{*}{ Fecal incontinence $>1$ / week } & Yes & $34(16.6 \%)$ \\
\hline & No & $171(83.4 \%)$ \\
\hline \multirow{2}{*}{ Retentive posturing } & Yes & $191(93.2 \%)$ \\
\hline & No & $14(6.8 \%)$ \\
\hline \multirow{2}{*}{ Painful defecation } & Yes & $185(90.2 \%)$ \\
\hline & No & $20(9.8 \%)$ \\
\hline \multirow{2}{*}{$\begin{array}{l}\text { Presence of large fecal mass in the } \\
\text { rectum }\end{array}$} & Yes & $46(22.4 \%)$ \\
\hline & No & $159(77.6 \%)$ \\
\hline \multirow{2}{*}{$\begin{array}{l}\text { History of large-diameter stools that } \\
\text { may obstruct the toilet }\end{array}$} & Yes & $180(78.8 \%)$ \\
\hline & No & $25(12.2 \%)$ \\
\hline
\end{tabular}

were considered as a functional problem. There are some reports about the correlation between constipation and reflux disease, but there is not any international consensus on this correlation. In the study by Bowrowitz and Sutphen, they concluded that many children with chronic upper intestinal symptoms suffered from chronic unrecognized constipation. ${ }^{1}$ The aim of the current study was to evaluate the relationship between functional constipation and GERD.

\section{MATERIALS AND METHODS}

This cross-sectional and observational study was conducted in Pediatric Gastroenterology Clinic of Shiraz University of Medical Sciences. Children aged $<16$ years with the diagnosis of functional constipation were included in the current study. Rome III criteria were used for defining constipation in infants ${ }^{2}$ and children ${ }^{3}$ in our study. Children with developmental delays, food allergy, organic problems, and thyroid disorders were excluded from the study.

205 patients were included in this study. Of them, 185 patients responded to questions without their parents' help, and 20 patients received help from their parents. The patients were categorized into two groups of 185 patients and 20 patients. GERDQ questionnaire was used for the first group, ${ }^{4}$ and I-GERD questionnaire was used for the second group. Score $>15$ was considered as a GERD for I-GERD. Score $>11$ was considered as a GERD in children.

\section{Data analysis:}

SPSS software version 19 was used for data analysis. Chi-square and Fisher's exact tests were used. $p$ value $<$ 0.05 was considered statistically significant.

\section{RESULTS}

In the current study 205 children (boys $=50.2 \%$, girl $=49.8 \%)$ were included. The mean age of the participants was $5.51 \pm 3.15$ years ranged from 6 months to 16 years. According to the degree of perception and responsiveness, the children were categorized into two groups consisting of 185 and 20 patients. In the second group, the questions responded by the parents. The mean onset of constipation was $32.27 \pm 31.04$ months (range: 1-156 months). The mean duration of constipation was 32.21 \pm 28.85 months (range: 1-162 months). The duration of treatment was $1.47 \pm 1.05$ years (range: $1-5$ years). Of the 205 children with constipation, 96 (46.8\%) had a positive family history of constipation, of them 62 $(64.5 \%)$ had first degree relatives with constipation, and $34(35.4 \%)$ had second-degree relatives with constipation.

Of all cases, $77.6 \%$ had received treatment before the study. Polyethylene glycol was the most frequently used drug for the treatment of constipation. In our study. $11.4 \%$ of the patients with constipation had GERD. And of the 20 infants, 8 (40\%) had GERD. Frequency of Rome III criteria among children was shown in Table 1. The most frequent criteria was retentive posturing ( $\mathrm{n}$ $=191,93.2 \%)$ and painful defection( $\mathrm{n}=185,90.2 \%)$. Result of GERDQ questionnaire was shown in table-2. GERD symptoms among infants and toddlers were shown in table-3. There was no correlation between Rome III criteria and gastroesophageal reflux disease (Table 4).

\section{DISCUSSION}

Functional constipation and GERD are among functional gastrointestinal disorders. The relationship between functional constipation and reflux disease has remained questionable.

The association between reflux symptoms and constipation was first described by Borowitz et al. They were reported 34 children with GERD who were resistant to classical therapy. Many of children underwent extensive laboratory and endoscopic examination. All children 
Table 2: The questions of GERDQ questionnaire asked from the children and adolescents in our study

\begin{tabular}{lccccc}
\hline \multicolumn{7}{c}{ How many times does this occur per week? } \\
\hline Questions & $\mathbf{0}$ & $\mathbf{1}$ day & $\mathbf{2 - 3}$ days & 4-7 days & Total \\
\hline Q1 & $112(60.5 \%)$ & $17(9.2 \%)$ & $18(9.7 \%)$ & $38(20.5 \%)$ & 185 \\
\hline Q2 & $137(74.1 \%)$ & $16(8.6 \%)$ & $13(7 \%)$ & $19(10.3 \%)$ & 185 \\
\hline Q3 & $87(47 \%)$ & $10(5.4 \%)$ & $23(12.4 \%)$ & $65(35.1 \%)$ & 185 \\
\hline Q4 & $145(78.4 \%)$ & $6(3.2 \%)$ & $8(4.3 \%)$ & $26(14.1 \%)$ & 185 \\
\hline Q5 & $146(78.9 \%)$ & $6(3.2 \%)$ & $10(5.4 \%)$ & $23(12.4 \%)$ & 185 \\
\hline Q6 & $172(93 \%)$ & $1(0.5 \%)$ & $10(5.4 \%)$ & $2(1.1 \%)$ & 185 \\
\hline
\end{tabular}

Q1: Burning sensation behind the breastbone (heartburn); Q2: Stomach contents moving up to the throat or mouth (regurgitation) Q3: Pain in the middle of the upper stomach area; Q4: Nausea; Q5: Trouble getting a good sleep during nights because of heartburn or regurgitation; Q6: Need for over-the-counter medicine for heartburn or regurgitation in addition to medicine your doctor prescribed

Table 3: GERD symptoms among the infants and toddlers participated in the study

\begin{tabular}{|c|c|c|c|c|c|c|}
\hline Variables & Never & Rarely & Sometimes & Often & Always & Total \\
\hline Spit up & $9(45 \%)$ & $3(15 \%)$ & $1(5 \%)$ & $3(15 \%)$ & $4(20 \%)$ & $20(100 \%)$ \\
\hline Feeding refusal & $9(45 \%)$ & $3(15 \%)$ & $1(5 \%)$ & $2(10 \%)$ & $5(25 \%)$ & $20(100 \%)$ \\
\hline Stop eating & $7(35 \%)$ & $5(25 \%)$ & $3(15 \%)$ & $2(10 \%)$ & $3(15 \%)$ & $20(100 \%)$ \\
\hline Cry after feeding & $14(70 \%)$ & $3(15 \%)$ & $0(0)$ & $0(0)$ & $3(15 \%)$ & $20(100 \%)$ \\
\hline Cry or fuss more than usual & $10(50 \%)$ & $6(30 \%)$ & $0(0)$ & $1(5 \%)$ & $3(15 \%)$ & $20(100 \%)$ \\
\hline How often did the baby have hiccups? & $7(35 \%)$ & $5(25 \%)$ & $5(25 \%)$ & $1(5 \%)$ & $2(10 \%)$ & $20(100 \%)$ \\
\hline $\begin{array}{l}\text { How often did the baby have an episode } \\
\text { of arching back? }\end{array}$ & $14(70 \%)$ & $2(10 \%)$ & $2(10 \%)$ & $2(10 \%)$ & $0(0)$ & $20(100 \%)$ \\
\hline
\end{tabular}

Table 4: Correlation between Rome III and gastroesophageal reflux disease

\begin{tabular}{|c|c|c|c|c|}
\hline Variables & & GERD (No) & GERD (No) & $p$ value \\
\hline \multirow{2}{*}{ Defecation $=<2 /$ week } & Yes & $104(50.7 \%)$ & $15(7.3 \%)$ & \multirow{2}{*}{0.45} \\
\hline & No & $72(35.1 \%)$ & $14(6.8 \%)$ & \\
\hline \multirow{2}{*}{ Fecal incontinence $>1$ week } & Yes & $32(15.6 \%)$ & $2(0.9 \%)$ & \multirow{2}{*}{0.17} \\
\hline & No & $44(70.2 \%)$ & $27(13.1 \%)$ & \\
\hline \multirow{2}{*}{ Retentive posturing } & Yes & $163(79.5 \%)$ & $28(13.6 \%)$ & \multirow{2}{*}{0.69} \\
\hline & No & $13(6.3 \%)$ & $1(0.4 \%)$ & \\
\hline \multirow{2}{*}{ Painful defecation } & Yes & $161(78.5 \%)$ & $24(11.7 \%)$ & \multirow{2}{*}{0.17} \\
\hline & No & $15(7.3 \%)$ & $5(2.4 \%)$ & \\
\hline \multirow{2}{*}{ Presence of large fecal mass } & Yes & $39(19 \%)$ & $7(3.4 \%)$ & \multirow{2}{*}{0.81} \\
\hline & No & $137(66.8 \%)$ & $22(10.7 \%)$ & \\
\hline \multirow{2}{*}{ History of large diameter that may obstruct the toilet } & Yes & $155(75.6 \%)$ & $25(12.1 \%)$ & \multirow{2}{*}{0.76} \\
\hline & No & $21(10.2 \%)$ & $4(1.9 \%)$ & \\
\hline
\end{tabular}

were found to have constipation. Following treatment of constipation, most of the children showed resolution of the GERD symptoms. ${ }^{1}$

In our study, constipation was more frequent among children with a positive family history of constipation. Similar findings were also reported. ${ }^{5}$

In another study by Baran and colleagues, significant improvement in the acid reflux index and symptoms of GERD was achieved after treatment of constipation. ${ }^{6}$

We found no significant correlation between Rome III criteria and GERD. In the study by Baran and others, a significant relationship between GERD and constipation was found. ${ }^{7}$ In their study, ${ }^{7} 39.5 \%$ of the participants had GERD. In our study, the diagnosis of GERD was made 
using clinical manifestations and questionnaires. But in the study by Baran and colleagues, $\mathrm{pH}$ metry was used for the diagnosis.

Another multicenteric study with more sample is recommended to find correlation between GERD symptoms and functional constipation among children.

Study limitation: Single-center study and lack of $\mathrm{pH}$ monitoring for the evaluation of GERD were the limitations of this study.

\section{ACKNOWLEDGMENT}

This study was approved by Vice-Chancellor for Research Affair of Shiraz University of Medical Sciences (No\#93-01-01-8890)

\section{ETHICAL APPROVAL}

There is nothing to be declared.

\section{CONFLICT OF INTEREST}

The authors declare no conflict of interest related to this work.

\section{REFERENCES}

1. Borowitz SM, Sutphen JL. Recurrent vomiting and persistent gastroesophageal reflux caused by unrecognized constipation. Clin Pediatr (Phila) 2004;43:461-6. doi: 10.1177/000992280404300507.

2. Hyman PE, Milla PJ, Benninga MA, Davidson GP, Fleisher DF, Taminiau J. Childhood functional gastrointestinal disorders: neonate/toddler. Gastroenterology 2006;130:1519-26. doi: 10.1053/j.gastro.2005.11.065.

3. Rasquin A, Di Lorenzo C, Forbes D, Guiraldes E, Hyams JS, Staiano A, et al. Childhood Functional Gastrointestinal Disorders: child/Adolescent. Gastroenterology 2006;130:1527-37. doi: 10.1053/j.gastro.2005.08.063.

4. Jones R, Junghard O, Dent J, Vakil N, Halling K, Wernersson B, et al. Development of the GerdQ, a tool for the diagnosis and management of gastro-oesophageal reflux disease in primary care. Aliment Pharmacol Ther 2009;30:1030-8. doi: 10.1111/j.1365-2036.2009.04142.x

5. Dehghani SM, Moravej H, Rajaei E, Javaherizadeh H. Evaluation of familial aggregation, vegetable consumption, legumes consumption, and physical activity on functional constipation in families of children with functional constipation versus children without constipation. Prz Gastroenterol 2015;10:89-93. doi: 10.5114/pg.2015.48996.

6. Baran M, Cagan Appak Y, Karakoyun M, Yalcinkaya
S, Eliacik K, Dundar B, et al. The overlap of gastroesophageal reflux disease and functional constipation in children: the efficacy of constipation treatment. Eur $J$ Gastroenterol Hepatol 2017;29:1264-1268. doi: 10.1097/ MEG.0000000000000979.

7. Baran M, Ozgenc F, Arikan C, Çakir M, Ecevit CO, Aydoğdu S, et al. Gastroesophageal reflux in children with functional constipation. Turk $J$ Gastroenterol 2012;23:634-8. doi: 10.4318/tjg.2012.0454.

8. Ekingen G, Ceran C, Guvenc BH, Tuzlaci A, Kahraman $\mathrm{H}$. Early enteral feeding in newborn surgical patients. Nutrition 2005;21:142-6. doi: 10.1016/j.nut.2004.10.003. 